\title{
REVIEW
}

\section{Latrepirdine: molecular mechanisms underlying potential therapeutic roles in Alzheimer's and other neurodegenerative} diseases

\author{
PR Bharadwaj ${ }^{1}$, KA Bates ${ }^{2}$, T Porter ${ }^{1}$, E Teimouri ${ }^{1}$, G Perry ${ }^{3}$, JW Steele ${ }^{4}$, S Gandy ${ }^{5}$, D Groth ${ }^{6}$, RN Martins ${ }^{1,7,8}$ and Giuseppe Verdile ${ }^{1,7,8,9}$
}

\begin{abstract}
Latrepirdine (Dimebon ${ }^{\mathrm{TM}}$ ) was originally marketed as a non-selective antihistamine in Russia. It was repurposed as an effective treatment for patients suffering from Alzheimer's disease (AD) and Huntington's disease (HD) following preliminary reports showing its neuroprotective functions and ability to enhance cognition in AD and HD models. However, latrepirdine failed to show efficacy in phase III trials in AD and HD patients following encouraging phase II trials. The failure of latrepirdine in the clinical trials has highlighted the importance of understanding the precise mechanism underlying its cognitive benefits in neurodegenerative diseases before clinical evaluation. Latrepirdine has shown to affect a number of cellular functions including multireceptor activity, mitochondrial function, calcium influx and intracellular catabolic pathways; however, it is unclear how these properties contribute to its clinical benefits. Here, we review the studies investigating latrepirdine in cellular and animal models to provide a complete evaluation of its mechanisms of action in the central nervous system. In addition, we review recent studies that demonstrate neuroprotective functions for latrepirdine-related class of molecules including the $\beta$-carbolines and aminopropyl carbazoles in AD, Parkinson's disease and amyotrophic lateral sclerosis models. Assessment of their neuroprotective effects and underlying biological functions presents obvious value for developing structural analogues of latrepirdine for dementia treatment.
\end{abstract}

Translational Psychiatry (2013) 3, e332; doi:10.1038/tp.2013.97; published online 3 December 2013

Keywords: Alzheimer's disease; latrepirdine; mechanism of action

\section{INTRODUCTION}

With an ageing population, there is a need for both preventative and disease-modifying treatments for Alzheimer's disease (AD). Current AD treatments target cognitive decline and provide only minor benefits across the array of clinical symptoms. ${ }^{1,2}$ Approved AD drugs such as acetylcholine esterase (ACE) inhibitors (donepezil, rivastigmine and galanthamine) and $\mathrm{N}$-methyl-D-aspartate (NMDA) receptor antagonists (Memantine) are generally prescribed as monotherapy or in combination. However, approved $A D$ drugs are expensive and, most importantly, do not prevent disease progression and are of limited benefit to most patients. ${ }^{3,4}$

Latrepirdine was initially used in Russia in 1983 as a nonselective antihistamine for the treatment of skin allergy and allergic rhinitis. ${ }^{5-7}$ Studies outlining the significance of antihistamine drugs in treating neurodegenerative disorders and the neuroprotective functions of latrepirdine in animal models initiated interest for repurposing latrepirdine as a potential therapy for AD and Huntington's disease (HD). Despite the lack of understanding of latrepirdine's mechanism of action in the central nervous system, it was evaluated in clinical trials for $A D^{8}$ and $\mathrm{HD}^{9}$ (Table 1). A pilot clinical trial performed on 14 patients with mild-moderate $A D$ supported the results of the cellular and animal studies. Significant improvement in both cognitive function and psychiatric symptoms was observed in all patients undergoing latrepirdine treatment. Also, a distinct antidepressive effect was observed in AD patients. ${ }^{5}$ In 2008, data from a phase II randomized, double-blind, placebo-controlled study conducted in Russia demonstrated for the first time, improvement across a range of clinical outcomes due to a therapeutic intervention in mild-moderate AD. ${ }^{8}$ Phase III trials, CONNECTION and CONTACT were then launched and results released in early March 2010 showed no improvement in any primary or secondary outcome measures of cognition in the patients. ${ }^{10}$ Similar to the outcomes in AD clinical trials, phase III trial of latrepirdine in HD patients failed to show efficacy in the 6-month HORIZON trial, which enrolled 403 people with $\mathrm{HD}$ in 11 countries. ${ }^{11}$ In contrast to the cognitive benefits observed in phase II trials, no significant improvements over placebo-treated patients were observed in HD patients administered latrepirdine. ${ }^{9}$

It is evident that latrepirdine trials in $H D$ and $A D$ have progressed to phase III trials based on an encouraging phase II trial data. It is although uncertain whether the failure of latrepirdine in phase III can be attributed to the poor efficacy of the drug or due to the lack of trial optimization. The benefits of

\footnotetext{
${ }^{1}$ Centre of Excellence for Alzheimer's Disease Research and Care, School of Medical Sciences, Edith Cowan University, Joondalup, WA, Australia; ${ }^{2}$ School of Animal Biology, The University of Western Australia, Crawley, WA, Australia; ${ }^{3}$ Department of Biology and UTSA Center for Neurosciences, University of Texas at San Antonio, San Antonio, TX, USA; ${ }^{4}$ Greengard Laboratory of Molecular and Cellular Neuroscience, Rockefeller University, San Antonio, NY, USA; ${ }^{5}$ Department of Neurology, Mount Sinai School of Medicine, Mt Sinai, NY, USA; ${ }^{6}$ School of Biomedical Sciences, CHIRI Biosciences Research Precinct, Faculty of Health Sciences, Curtin University, Bentley, WA, Australia; ${ }^{7}$ School of Psychiatry and Clinical Neuroscience, University of Western Australia, Crawley, WA, Australia; ${ }^{8}$ The Sir James McCusker Alzheimer's Disease Research Unit, Hollywood Private Hospital, Nedlands, WA, Australia and ${ }^{9}$ School of Public Health, Faculty of Health Sciences, Curtin University, Bentley, WA, Australia. Correspondence: Dr G Verdile, Centre of Excellence for Alzheimer's Disease Research and Care, School of Medical Sciences, Edith Cowan University, Building 17, Level 3, 270 Joondalup Drive, Joondalup 6027, WA, Australia. E-mail: g.verdile@ecu.edu.au
}

Received 5 August 2013; revised 19 September 2013; accepted 26 September 2013 


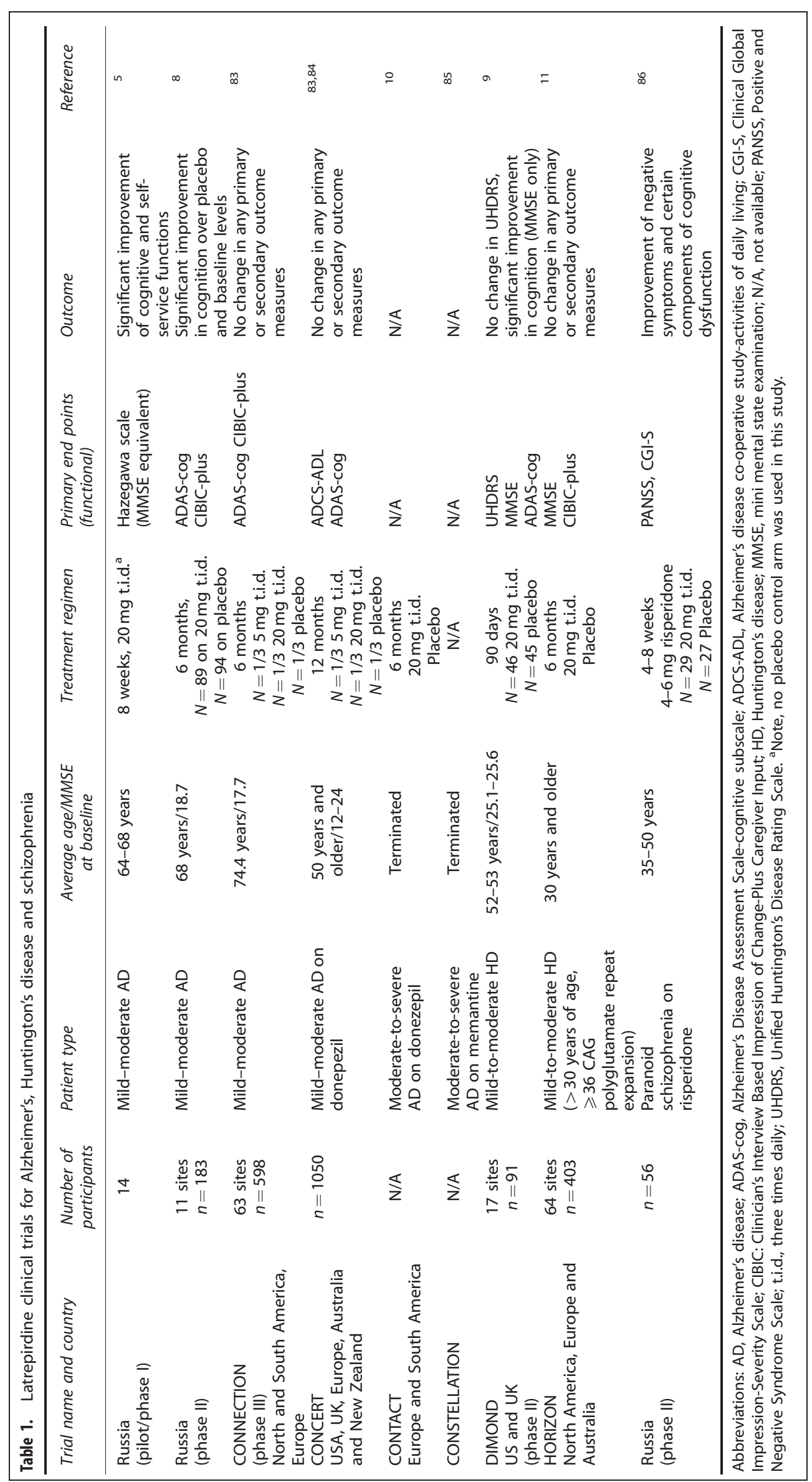


latrepirdine in the phase II AD study were not driven by worsening in the placebo group, but reflected an absolute improvement on latrepirdine as well as a decline on placebo. In the phase III trial, however, the patients in the trial did not deteriorate significantly in either the drug-treated group or the placebo group, which makes interpretation of the study more difficult. There are also some notable differences between the Russian phase II study and the multinational phase III studies including the formulation of latrepirdine, baseline mini mental state examination (MMSE) and the age of the patients recruited (mean age 68.1 years in phase II versus 74.4 years in phase III). ${ }^{8,10}$ Unfortunately, concerning the disease-modifying activity of latrepirdine, no brain amyloid load (Pittsburgh Compound-B-positron emission tomography (PIB-PET) imaging) or biomarker data are available from the different clinical trials as only ADAS-cog (Alzheimer's Disease Assessment Scalecognitive subscale) was used as primary outcome.

One of the other major criticisms for the mixed outcomes from the $A D$ and HD clinical trials was directed toward the lack of optimization of the trial design and the lack of clarity in the drug's mechanism of action responsible for its cognitive-enhancing properties. Several possible neuroprotective functions for latrepirdine have been postulated; however, there is a need to rigorously test and verify the mechanisms of action of latrepirdine and establish the dose that is most likely to be effective. ${ }^{12,13}$ In addition to its well-known antihistamine properties, studies have demonstrated cognitive-enhancing properties in non-transgenic healthy animal models and in neurodegenerative models., 14-16 Studies have reported latrepirdine's ability to inhibit a number of neurotransmitter receptors, modulate $\mathrm{Ca}^{2}+$ metabolism, protect mitochondrial function ${ }^{5,17,18}$ and more recently its ability to modulate intracellular catabolic pathways and reduce amyloid aggregates and pathology in cellular and mice models. ${ }^{15,19-22}$ Unfortunately, target validation and the magnitude of the impact of these putative actions on key disease processes and clinical symptoms have not been robustly clarified. Here, we review the studies investigating the different mechanisms of action of latrepirdine in cellular and animal models, to evaluate its potential role in the treatment of $A D$ and other neurodegenerative diseases.

\section{MECHANISMS OF ACTION}

\section{Antihistamine and cognitive properties}

Latrepirdine blocks $\mathrm{H} 1$ histamine receptor activity and hence was used as an antihistamine drug for the treatment of burns, allergic rhinitis and skin allergy in Russia since 1983. However, its use as an antihistamine declined with the discovery of more selective drugs. ${ }^{6,23}$ Studies also have reported antiarrhythmic properties and an effect on coronary blood flow and myocardial contractibility, ${ }^{24,25}$ even though the possible underlying mechanisms have not yet been determined. More recently, interest in latrepirdine rebounded following a growing interest in the role of histamine receptors (5-hydroxytryptamine $6(5-\mathrm{HT} 6)$ and 5-HT7) in learning and cognitive functions ${ }^{26,27}$ and studies reporting cognitiveenhancing and neuroprotective functions of latrepirdine. ${ }^{5,15}$ In addition to blocking the histamine receptor activity, latrepirdine has been shown to interact with calcium channels and a wide range of other neurotransmitter receptors.

\section{Multireceptor activity and modulation of calcium channels}

Neurotoxicity and loss of neuronal processes caused by excitatory amino acids, glutamate and aspartate is a characteristic feature of several neurodegenerative diseases. The toxic action of glutamate and aspartate is largely receptor-mediated leading to an increase in the intracellular $\mathrm{Ca}^{2+}$ concentration that triggers a cascade of pathological reactions causing the death of nerve cells. ${ }^{28,29}$ Studies indicate that intracellular calcium $\left(\mathrm{Ca}^{2+}\right)$ flux is critical in synaptic plasticity, a cellular mechanism for learning and memory. Therefore, modulators of $\mathrm{Ca}^{2+}$ channels and receptor functions regulating calcium influx are currently a focus of interest for their potential use as neuroprotective agents. ${ }^{30-32}$ In the Bachurin et al. ${ }^{5}$ study, latrepirdine suppressed $\mathrm{Ca}^{2+}$-induced contractions of smooth muscles in a reversible and concentration-dependent manner. Similar effects of latrepirdine were observed in neuronal cultures from wild-type mice and HD transgenic mice, which harbour the entire human $H D$ gene containing 128 CAG repeats. Also, latrepirdine was found to act as an inhibitor of NMDA receptors and voltage-gated calcium channels. Application of latrepirdine stabilized glutamate-induced $\mathrm{Ca}^{2+}$ signals and conferred protection from glutamate-induced apoptosis. ${ }^{16}$

In one of the initial studies, the effects of latrepirdine on AMPA ( $\alpha$-amino-3-hydroxy-5-methyl-4-isoxazolepropionic acid) and NMDA subtypes, glutamate receptors in rat cerebral neurons, were evaluated in a comparative study against memantine, a potent NMDA receptor antagonist. ${ }^{33}$ Both latrepirdine and memantine in low concentrations potentiated activity of AMPA receptors in rat cerebellar Purkinje cells. In rat cortical neurons, both latrepirdine and memantine efficiently blocked NMDA receptor activity with different potencies. The differences in the effects of memantine and latrepirdine may be determined by their interaction with different channel and/or receptor subunits of NMDA receptors. For example, the polyamine site of the NMDA receptor NR2B subunit ${ }^{34}$ has been suggested as a possible binding site for latrepirdine.

Interactions between latrepirdine and a number of molecular targets including ACEs, $\alpha$-adrenergic, serotonergic and dopaminergic receptors have been reported. ${ }^{5,33,35,36}$ These receptors are widely distributed in the brain and are associated with different neuropsychiatric symptoms ${ }^{37,38}$ including hallucinations and depression in $A D$ patients. ${ }^{39,40}$ Evaluation of latrepirdine against a set of biochemical targets indicated that it inhibits $\alpha$-adrenergic receptors $(\alpha 1 \mathrm{~A}, \alpha 1 \mathrm{~B}, \alpha 1 \mathrm{D}$ and $\alpha 2 \mathrm{~A})$, histamine $\mathrm{H} 1$ and $\mathrm{H} 2$ receptors and serotonin 5 -HT2c, 5-HT5A and 5-HT6 receptors. ${ }^{16,41}$

In a recent study, molecular pharmacology profiling of latrepirdine was performed on a panel of 70 targets including enzymes, ion channels, neurotransmitter transporters and G-protein-coupled receptors to characterize the spectrum of its activity. ${ }^{17}$ In addition to histaminergic receptors, latrepirdine exhibited high affinity to a range of other receptors; specifically, serotonergic, $\alpha$-adrenergic and dopaminergic receptors. Latrepirdine was found to interact with relatively low affinity with some ion channels (benzothiazepine site of L-type $\mathrm{Ca}^{2+}$ channel, site 2 of sodium channel and hERG (human ether-a-gogo-related gene) potassium channel) and the norepinephrine transporter. Owing to its broad spectrum activity on many therapeutically important neuronal receptors, it is unclear how latrepirdine's molecular pharmacology relates to its multifunctional effects on different aspects of central nervous system activity.

Neuroprotective and cognitive-enhancing functions in animal models

Latrepirdine has been shown to possess neuroprotective functions and improve memory in animals with drug-induced cognitive impairment. In the initial work by Shadurskaia et al., ${ }^{42}$ latrepirdine was shown to possess neuroactive functions including its ability to inhibit monoamine oxidase deaminating dopamine and serotonin, thereby increasing dopamine and noradrenaline in the rat brain. ${ }^{42}$ It was shown that latrepirdine is a potent competitive and reversible inhibitor of both ACE and butyrylcholine esterase, which are key enzymes associated with the degradation of acetylcholine in the brain. ${ }^{43}$

Systemic administration of latrepirdine restored memory as determined by two-way active avoidance performance in rats 
injected with AF64A (L-ethyl-1-(2-hydroxyethyl) aziridinium, a neurotoxic analogue of acetylcholine that causes neurodegenerative changes characteristic of $\mathrm{AD}^{44}$ The data suggested that latrepirdine activated compensatory mechanisms against chronic partial deprivation of cerebral cholinergic functions, which may be responsible for the prevention of neurodegeneration in AF64Ainjected rats. ${ }^{15}$ In a subsequent study, latrepirdine showed a dosedependent prevention of convulsions and death caused by NMDA-induced toxicity in mice and protected cerebellar granule cells against $\beta$-amyloid 25-35 (A $\beta 25-35)$, a neurotoxic fragment of $A \beta$ protein. ${ }^{5}$ Latrepirdine also increased survival rate of serumstarved differentiated neuroblastoma cells. ${ }^{18}$

In a more recent study, latrepirdine administered before methamphetamine significantly reduced the amount of striatal dopamine depletion in mice, suggesting that latrepirdine may be exerting a neurotoxin-specific protective effect. ${ }^{45}$ Besides its neuroprotective effects, administration of latrepirdine has also shown to promote hippocampal-dependent learning in both appetitive and inhibitory tasks in mice. ${ }^{46}$ However, in a more recent report, latrepirdine failed to exert any effect on the agerelated impairment in spatial learning and performance assessed using the Morris water maze. Latrepirdine also showed no effect on the age-related increase in hippocampal expression of markers of microglial and astroglial activation in rats. ${ }^{47}$ This study suggests that the cognitive-enhancing and neuroprotective properties of latrepirdine may be limited to the degeneration of specific neuronal functions and associated cognitive abilities. In addition to rodent models, latrepirdine has been shown to enhance memory and learning in a primate model. Acute latrepirdine administration was associated with modest improvements in the performance of a delayed matching to sample task in young adult and aged monkeys and showed a trend towards attenuation of scopolamine-induced impairments in young adult monkeys. ${ }^{48}$

Recent studies have provided further insight into the potential mechanisms of action that may underlie latrepirdine's cognitiveenhancing properties. Acute oral administration of latrepirdineenhanced cognition in rats but did not alter the activity of acetylcholine (ACE) nor block NMDA-induced calcium influx, suggesting that the cognition-enhancing effects of latrepirdine are unlikely to be mediated by ACE inhibition or NMDA receptor antagonism. ${ }^{49}$ Latrepirdine was compared against SB-399885 (selective 5 -HT6 antagonist ${ }^{50}$ ) to evaluate the role of antihistamine activity to cognitive functions. The affinity and potency of latrepirdine for 5-HT6 receptor were significantly lower than that observed with the selective 5-HT6 antagonist SB-399885. Consistent with its activity at the 5-HT6 receptor, latrepirdine was significantly less potent than SB-399885 in the improvement of memory functions. ${ }^{41}$ It is important to note that latrepirdine interacts with several other receptor molecules and that these interactions have not been fully characterized. As many of these targets significantly impact cognitive function, the relative role of 5-HT6 receptor antagonism in the clinical efficacy of latrepirdine remains speculative. Latrepirdine was also found to be proneurogenic in an in vivo screen in adult mice. ${ }^{19}$ Although it showed lower activity compared with the lead compound P7C3, an aminopropyl carbazole, latrepirdine administration showed significant increase in hippocampal neurogenesis in the mouse model. ${ }^{19}$ This study provided further evidence for latrepirdine's cognitive-enhancing properties; however, no specific target or mechanism responsible for its actions was indicated.

Latrepirdine treatment in neurodegenerative disease models

Recent studies provide evidence for a neuroprotective effect of latrepirdine in transgenic mouse models of neurodegenerative disease. Latrepirdine has been shown to modulate amyloid pathology, reduce memory deficits in transgenic $A D$ mice and protect against $A \beta$ toxicity in cultured cells..$^{5,18,51}$ TgCRND8 mice ${ }^{52}$ treated with latrepirdine exhibited a trend towards cognitive and behavioural improvement without affecting the levels of total $A \beta$ in the brain. ${ }^{53}$ In our recent work, TgCRND8 mice were administered with latrepirdine and subjected to behaviour analysis in the cued and contextual fear conditioning paradigm, as well as immunohistological and biochemical analysis of AD-related neuropathology. Latrepirdine treatment was associated with improved learning behaviour and with a reduction in the accumulation of $A \beta 42$ and $\alpha$-synuclein. ${ }^{21,22}$

The effects of latrepirdine have also been studied in other neurodegenerative disease models including Parkinson's disease (PD) and amyotrophic lateral sclerosis (ALS). In an overexpressing synuclein mice model (Thy $1 \mathrm{~m} \gamma \mathrm{SN}$ ), chronic administration of latrepirdine was shown to significantly reduce the development of motor dysfunction and coordination. ${ }^{14}$ However, a more recent study showed no improvement in motor skills or changes in the levels of striatal dopamine or $\alpha$-synuclein in the brains of transgenic mouse model characterizing early-stage PD. ${ }^{54}$ Also, latrepirdine did not block 1-methyl-4-phenyl-1,2,3,6-tetrahydropyridine (MPTP)-mediated cell death of dopaminergic neurons in Caenorhabditis elegans or in the substantia nigra of adult mice. ${ }^{55}$ Chronic latrepirdine administration was studied in a mouse model of $\gamma$-synucleinopathy characteristic of the pathological features of ALS. Significant improvement of motor performance, reduced amyloid inclusions, decreased amount of insoluble $\gamma$-synuclein species and a notable amelioration of astrogliosis were observed in the latrepirdine-treated animal groups. ${ }^{56}$ However, in a more recent study, latrepirdine did not protect the spinal cord motor neurons from cell death or preserved the motor function in a mouse model of ALS. ${ }^{57}$ Latrepirdine treatment also conferred no protection against the toxicity associated with expression of ALS-associated genes TDP43 and FUS, and the HD-associated protein huntingtin with a 103 copy-polyglutamine expansion (htt$103 \mathrm{Q}$ ) in yeast. These results indicate that latrepirdine's neuroprotective functions are limited to specific neurodegenerative mechanisms. Further analysis of latrepirdine's proposed neuroprotective effects and pathological markers including the accumulation of the misfolding protein, levels of neurotransmitters and receptor activities in these disease models can provide a greater insight into its mechanisms of action in vivo.

There is increasing evidence describing latrepirdine's neuroprotective effects, but the mechanisms underlying these cognitive benefits have remained elusive. During the past few decades, the concept of multitarget drug activity has been proposed. ${ }^{58,59}$. On the basis of this concept, the mechanisms responsible for the beneficial actions of latrepirdine may be attributed to multiple downstream effects on a number of receptors leading to change in neurotransmitter levels.

\section{Mitochondrial activity}

Mitochondrial dysfunction is a common feature of several neurodegenerative diseases including $A D$. In the $A D$ brain, there is a characteristic decrease in the number of mitochondria in neurons accompanied by decreased brain glucose metabolism, ${ }^{60}$ and reduced activities of both tricarboxylic acid cycle enzymes ${ }^{61}$ and cytochrome $c$ oxidase. ${ }^{62,63}$ A number of studies have reported the protective effects of latrepirdine on mitochondrial structure, function and metabolism, some of which have also been indicated as the underlying mechanism of its proneurogenic properties. In the initial report, latrepirdine was shown to modulate the mitochondrial permeability transition pore (PTP). PTP regulates the transport of $\mathrm{Ca}^{2+}$ and smaller compounds in and out of the mitochondria. Latrepirdine suppressed the opening of PTP by neurotoxins including MPP + (1-methyl-4-phenylpyridinium), A $325-35$, phosphate ions, calcium ions or by butylhydroxyperoxide in isolated rat liver mitochondria. ${ }^{35}$ In the same study, latrepirdine was shown to suppress lipid peroxidation induced by 
either butylhydroperoxide or by $A \beta 25-35$. Although no direct evidence for the relationship between suppression of lipid peroxidation and inhibition of PTP opening was identified, these properties may be a contributing factor in the protection of mitochondrial function and in the overall neuroprotective effect of the latrepirdine. ${ }^{35}$ In a more recent study, similar effects of latrepirdine on calcium-induced permeability transition were observed in the mitochondria isolated from rat brain. Latrepirdine attenuated $\mathrm{Ca}^{2+}$-induced swelling but did not alter cytochrome $c$ release or $\mathrm{Ca}^{2+}$ uptake capacity. The findings showed that latrepirdine reduced mitochondrial swelling without inducing any major changes in permeability transition. ${ }^{64}$

In primary mouse cortical neuronal cells and human neuroblastoma cells, latrepirdine improved mitochondrial function on aspects such as mitochondrial membrane potential and ATP synthesis, although the drug's effect on PTP opening was not determined. ${ }^{18}$ Also, no change in the mitochondrial DNA copy number was observed with latrepirdine treatment, implying no effect on mitochondrial biogenesis. ${ }^{18}$. In an in vivo screen for search of novel proneurogenic compounds, latrepirdine was shown to protect mitochondrial membrane integrity at high concentrations. ${ }^{19}$ In a more recent study, the effects of latrepirdine were tested on mitochondrial function and dynamics in a cellular model, overexpressing neurotoxic $A \beta$ peptides. Here, latrepirdine was shown to protect against the toxic effects of $A \beta$ on mitochondrial morphology, respiratory chain complex activities and enlarged mitochondrial mass. ${ }^{65}$ Further support for the potential role of latrepirdine in the enhancement of mitochondrial function and subsequent energy homeostasis comes from one study that showed latrepirdine to be significantly enhanced by cerebral glucose utilization in aged mice, whereas no effect on CGU was observed in the young mice. ${ }^{66}$

\section{Regulate protein aggregation}

Progressive accumulation of misfolded or aggregate proteins in the brain is a characteristic feature of neurodegenerative diseases including ALS (TAR DNA-binding protein 43, TDP-43), PD (synuclein), HD (Huntington protein, $\mathrm{mHTT}$ ) and AD (beta amyloid, $A \beta)$. Agents that reduce aggregation and accumulation of amyloidogenic proteins in the brain have shown to improve or arrest the cognitive deficits and behavioural symptoms in animal models. ${ }^{67-69}$ Recent studies have suggested that the ability to modulate accumulation or generation of protein aggregates in the brain may contribute to the neuroprotective and cognitiveenhancing functions of latrepirdine.

The effects of latrepirdine on the formation of TDP-43 aggregates were investigated in human neuroblastoma cells. Latrepirdine treatment reduced the number of TDP-43 aggregates as measured by immunoblot analysis. In combination with methylene blue, latrepirdine treatment further reduced the level of aggregates in cells. ${ }^{70}$ Latrepirdine treatment significantly reduced the number of amyloid deposits in the spinal cord associated with reduced development of motor dysfunction and astrogliosis in the Thy $1 \mathrm{~m} \gamma \mathrm{SN}$ mouse model. ${ }^{14}$ In a more recent study, the effects of latrepirdine on the formation of fibrillar detergent-insoluble structures formed by GS protein (the main component of pathological intracellular incorporations in the neurons of Thy $1 \mathrm{~m} \gamma \mathrm{SN}$ mice) were studied. ${ }^{71}$ This study revealed a significant reduction of aggregated synuclein forms in specimens of spinal cord tissue from latrepirdine-treated mice. However, no change in the levels of intermediate protein aggregation products, oligomers and protofibrils was observed with latrepirdine treatment.

In a more recently published work, the effects of latrepirdine upon $A \beta$, tau and astrogliosis in the hippocampus of triple transgenic $(3 \times \mathrm{Tg}-\mathrm{AD})$ mice was evaluated. A significant reduction in hippocampal/subicular APP/A $\beta$ in latrepirdine-treated mice was shown; however, no change in the levels of full-length APP, soluble $A \beta 1-40$ and $A \beta 1-42, A \beta$ oligomers, glial fibrillary acidic protein, beta-site APP cleaving enzyme 1 and hippocampal tau levels was observed. Interestingly, the number of the hippocampal APP/A $\beta$ plaques in latrepirdine-treated mice was higher compared with control mice. ${ }^{20}$ It is possible that latrepirdine accelerates the deposition of insoluble $A \beta$ into plaques without changing the levels of soluble $A \beta$ species. ${ }^{53}$ Overall these findings provide evidence for latrepirdine's ability to modulate protein aggregation. Although there is currently no evidence of latrepirdine's ability to significantly alter amyloid structure, recent studies have identified other metabolic functions that may be responsible for its ability to modulate protein aggregation. In a study by Steele et al., ${ }^{72}$ latrepirdine treatment elevated levels of $A \beta$ in the extracellular media in mouse N2a neuroblastoma cells and in isolated synaptoneurosomes from $A D$ transgenic mice (TgCRND8). In addition, an acute dose of latrepirdine administered intraperitoneally led to an increased $A \beta$ concentration in the interstitial fluid of $A D$ transgenic mice. This study showed a surprising association of acute latrepirdine dosing with elevated levels of extracellular $A \beta$. It is suggested that latrepirdine-induced changes in neurotransmission, coupled with altered synaptic activity may account for the rapid changes in extracellular $A \beta$ levels. Recent reports have shown that synaptic activity can dynamically alter interstitial fluid $A \beta$ levels in vivo; however, the specific mechanisms responsible for latrepirdine's effects are unclear. $^{72-74}$ In addition to modulating APP/A $\beta$ metabolism, recent reports have shown latrepirdine to enhance activity of intracellular protein degradation pathways such as autophagy.

\section{Latrepirdine modulates protein degradation pathways}

The autophagy-lysosome system represents a main intracellular degradation pathway for clearance of protein aggregates and damaged organelles in eukaryotic cells. ${ }^{75}$ Modulating the cellular degradation pathways to enhance clearance of protein aggregates is gaining interest as a therapeutic strategy in several neurodegenerative disorders featuring abnormal protein accumulation. In our recent report, a yeast model (Saccharomyces cerevisiae) was used to investigate whether latrepirdine can modulate autophagy and reduce levels of $A \beta 42$ aggregates. It was shown that latrepirdine upregulated yeast autophagic markers including vacuolar (lysosomal) activity and increased transport of Atg8 (autophagy-related protein 8) to the vacuole. Using an in vitro GFP-tagged $A \beta$ yeast expression system, we showed that latrepirdine significantly reduced GFP-A $\beta 42$ in wild-type compared with the autophagy-deficient mutant (Atg8 $\Delta$ ). Further, latrepirdine treatment attenuated $A \beta 42$-induced toxicity in wildtype cells but not in the Atg $8 \Delta$ mutant. Taken together, these findings provided evidence for a novel mechanism of action for latrepirdine in reducing intracellular accumulation of $A \beta 42$ and attenuation of $A \beta$ oligomer-induced toxicity via activation of autophagy. ${ }^{51}$

Similar observations of latrepirdine-induced autophagy were demonstrated in mammalian models. ${ }^{21,22}$ Treatment of cultured mammalian cells with latrepirdine led to enhanced mammalian target of rapamycin- and Atg5-dependent autophagy. Also, latrepirdine treatment of TgCRND8 transgenic mice was associated with improved learning behaviour and with a reduction in accumulation of $A \beta 42$ and $\alpha$-synuclein. The induction of autophagy was associated with decreased intracellular $A \beta$ accumulation and a trend towards increased secreted $A \beta$. These changes are consistent with the previous report showing that latrepirdine stimulates secretion of APP metabolites, ${ }^{72}$ suggesting that latrepirdine may reduce intracellular APP/A $\beta$ accumulation through stimulation of intracellular catabolic pathways. ${ }^{22}$ Latrepirdine was also shown to protect yeast against cytotoxicity associated with $\alpha$-synuclein expression, and this appeared to 
Table 2. Mechanisms of action: latrepirdine

\begin{tabular}{|c|c|c|}
\hline Cellular target/pathway & Drug activity & Reference \\
\hline \multirow{6}{*}{$\begin{array}{l}\text { Ion channels and } \\
\text { receptor activity }\end{array}$} & & 5 \\
\hline & Interacts with L-type $\mathrm{Ca}^{2+}$ channel, sodium channel, hERG potassium channel and transporter for & 17 \\
\hline & norepinephrine & 6,7 \\
\hline & Blocks histamine receptor $(\mathrm{H} 1$ and $\mathrm{H} 2)$ activity & 37 \\
\hline & Inhibits NMDA receptors and potentiates activity of AMPA-receptors & 17 \\
\hline & $\begin{array}{l}\text { Inhibits } \alpha \text {-adrenergic receptors }(\alpha 1 \mathrm{~A}, \alpha 1 \mathrm{~B}, \alpha 1 \mathrm{D} \text {, and } \alpha 2 \mathrm{~A}) \text {, imidazoline } 12 \text { receptor and serotonin } 5 \text {-HT2C, } \\
5-\mathrm{HT} 5 \mathrm{~A}, 5 \text {-HT6 receptors }\end{array}$ & \\
\hline \multirow[t]{6}{*}{ Mitochondrial activity } & Modulate the mitochondrial PTP and suppresses opening of PTP induced by neurotoxins & 39 \\
\hline & Attenuates $\mathrm{Ca}^{2+}$-induced mitochondrial swelling & 68 \\
\hline & Improves mitochondrial function on aspects such as mitochondrial membrane potential and ATP synthesis & 18 \\
\hline & Protects mitochondrial membrane integrity & 19 \\
\hline & Enhanced CGU in aged mice & 70 \\
\hline & $\begin{array}{l}\text { Restore the toxic effects of } A \beta \text { on mitochondrial morphology, respiratory chain complex and enlarged } \\
\text { mitochondrial mass }\end{array}$ & 69 \\
\hline \multirow[t]{5}{*}{ Protein aggregation } & Reduces the number of TDP-43 aggregates in neuroblastoma cells & 74 \\
\hline & Reduces the number of amyloid deposits in the spinal cord of over expressing $\gamma$-synuclein mice & 14 \\
\hline & Reduces accumulation of hippocampal/subicular APP/A $\beta$ and $\alpha$-synuclein in mice & $20-22$ \\
\hline & Elevates secretion of $A \beta$ in the extracellular media in neuronal cells and AD transgenic mice & 76 \\
\hline & Reduces GFP-A $\beta 42$ in wild-type compared with the autophagy-deficient mutant (Atg8 $\Delta$ ) in yeast model & 55 \\
\hline \multirow{3}{*}{$\begin{array}{l}\text { Protein degradation } \\
\text { pathways }\end{array}$} & Upregulates autophagic markers in yeast model & 55 \\
\hline & Enhances mTOR- and Atg5-dependent autophagy cultured mammalian cells & 22 \\
\hline & Shows increased UPS activity in over expression $\gamma$-synuclein mice model & 75 \\
\hline \multirow{10}{*}{$\begin{array}{l}\text { Neuroprotective } \\
\text { functions }\end{array}$} & \multirow{2}{*}{$\begin{array}{l}\text { Inhibits MAO deaminating dopamine and serotonin, decrease dopamine metabolism and increase } \\
\text { noradrenaline level in the rat brain }\end{array}$} & 46 \\
\hline & & 47 \\
\hline & Inhibits of both acetylcholine esterase and butyrylcholine esterase. & 15 \\
\hline & Restores TWAA performance in rats injected with AF64A & 5 \\
\hline & Prevents development of convulsions and death caused by NMDA induced toxicity in mice & 50 \\
\hline & \multirow{2}{*}{$\begin{array}{l}\text { Reduces amphetamine induced striatal dopamine depletion in mice and promote hippocampus- } \\
\text { dependent learning in both appetitive and inhibitory tasks in mice }\end{array}$} & 52 \\
\hline & & 19 \\
\hline & Enhance memory and learning in a primate model & 14 \\
\hline & Increases hippocampal neurogenesis in the mouse model & 22 \\
\hline & $\begin{array}{l}\text { Reduces the development of motor dysfunction in overexpressing synuclein mice model } \\
\text { Improves spatial memory function and behaviour in } A D \text { transgenic mice }\end{array}$ & $5,18,55$ \\
\hline
\end{tabular}

Abbreviations: A $\beta, \beta$-amyloid; AD, Alzheimer's disease; AMPA, $\alpha$-amino-3-hydroxy-5-methyl-4-isoxazolepropionic acid; Atg5, autophagy-related protein 5; CGU, cerebral glucose utilization; hERG, human ether-a-go-go-related gene; MAO, monoamine oxidase; mTOR, mammalian target of rapamycin; NMDA, N-methyl-Daspartate PTP, permeability transition pore; TDP-43, TAR DNA-binding protein 43; TWAA, two-way active avoidance; UPS, ubiquitin proteosome.

occur via induction of autophagy. Latrepirdine also stimulated the degradation of $\alpha$-synuclein in differentiated human neuroblastoma cells, and in mouse brain following chronic administration, in parallel with elevation of the levels of markers autophagic activity. ${ }^{21}$ In a more recent study, latrepirdine-treated Thy $1 \mathrm{~m} \gamma \mathrm{SN}$ mice showed increased ubiquitin proteosome activity, suggesting that it also stimulates other intracellular systems, in addition to autophagy, that may contribute to the elimination of pathological protein aggregates.

\section{SYNTHESIS AND ACTIVITY OF LATREPIRDINE-RELATED COMPOUNDS}

Latrepirdine is a small heterocyclic molecule with different conformations and a relatively complicated pharmacology. As described above latrepirdine can modulate receptor activity, protect mitochondrial function, modulate intracellular catabolic pathways and reduce amyloid aggregates and pathology in cellular and neurodegenerative mice models (Table 2). A wide range of cellular functions and broad concentration ranges $(0.1-100 \mu \mathrm{m})$ are required to achieve latrepirdine's proposed biological activities. Some of these drug interactions have also been suggested to be important for its cognitive-enhancing functions; however, it has been difficult to identify one particular pathway as a target for latrepirdine in $A D$ and other neurodegenerative diseases.

Latrepirdine is known for its wide array of neuronal functions and hence synthesis of structural analogues and assessment of their effects on the therapeutic targets presents obvious value for developing novel drugs for dementia treatment. In an attempt to isolate potent histamine receptor antagonists, a recent study tested synthesized latrepirdine analogues of 2,3,4,5-tetrahydro$1 \mathrm{H}$-pyrido[4,3-b]indoles 3 and 4 for their ability to interact with histamine $\mathrm{H} 1$ receptors. ${ }^{76}$ The novel compounds demonstrated much higher affinity to all of the receptors studied as compared with latrepirdine. Steric orientation of 5-styryl substitution was shown to have an important role in the affinity of the molecules to 5-HT6 and $\mathrm{H} 1$ receptors. The specificity profiles showed that similar to latrepirdine, the new 2,3,4,5-tetrahydro- $1 \mathrm{H}$-pyrido $[4,3-b]$ indoles 3 and 4 display a broad spectra of potential pharmacological activities including adrenergic, dopaminergic, histaminergic, serotonergic as well as some ion channel targets. Although promising, the biological activity of these novel compounds will require further assessment and target validation in cellular and animal models.

Latrepirdine contains a backbone structure of $\beta$-carboline (9H-pyrido[3,4-b]indole), a bioactive class of compounds found naturally in alkaloids produced in plants and known for their 
broad spectrum biological activity. The family of $\beta$-carboline alkaloids, characterized by a core indole structure and a pyridine ring affect multiple central nervous system targets. These include the 5-hydroxytryptamine receptor subtypes $5-\mathrm{HT} 2$ and 5 -HT1 $\mathrm{A}^{77}$ the NMDA receptor, ${ }^{78}$ monoamine oxidase- $\mathrm{A}^{79}$ and dopaminergic signaling pathways. ${ }^{80,81}$ In addition to these targets, the $\beta$-carboline alkaloid, harmine, has recently been reported to be a high-affinity inhibitor of dual-specificity tyrosine phosphorylation-regulated kinase $1 \mathrm{~A}$ activity, a member of the dualspecificity tyrosine phosphorylation-regulated kinase family that has a significant role in signaling pathways regulating cell proliferation involved in brain development. ${ }^{82} \mathrm{~A}$ new class of carboline compound that enhance hippocampal neurogenesis and ameliorate cognitive decline were identified in an in vivo screen in search of chemicals capable of enhancing neuron formation in adult mice. In more recent studies, P7C3 has shown the ability to reduce neurodegeneration in ALS and PD models. P7C3 was shown to block MPTP-mediated cell death of dopaminergic neurons in the substantia nigra of adult mice, a model of $\mathrm{PD}^{55}$ and protect spinal cord motor neurons from cell death in the G93A-SOD1 mutant mouse model of ALS. ${ }^{57}$ These observations provide further evidence for the neuroprotective functions of the carboline scaffold and raise the possibility that latrepirdine and $\mathrm{P} 7 \mathrm{C} 3$ compounds may operate via a common mechanistic pathway.

\section{CONCLUSION}

To date, no preventive or disease-modifying drugs are available for the treatment of neurodegenerative diseases including $A D$, the leading cause of dementia. Studies have demonstrated neuroprotective functions for latrepirdine and related class of molecules including the $\beta$-carbolines and aminopropyl carbazoles. However, the precise mechanism(s) underlying their cognitive benefits in AD, HD and other neurodegenerative disease models is unclear. Further investigation of the specific cellular targets and biochemical pathways underlying their neuroprotective functions in disease models can provide the basis for structure-based drug design. Such target-specific compounds may offer promise for the future in the treatment of neurodegenerative diseases.

\section{CONFLICT OF INTEREST}

SG holds research grant support from Amicus Pharmaceuticals, and is a consultant to Pfizer-Janssen Alliance.

\section{ACKNOWLEDGMENTS}

We acknowledge financial support from The McCusker Foundation for Alzheimer's disease Research, NHMRC funding (Project Grant APP1009295 to RM, GV and SG) and the Neurotrauma Research Program (KAB). The funding sources had no role in study design, collection, analysis and interpretation of data, the writing of and decision to publish this commentary.

\section{REFERENCES}

1 Omerovic M, Teipel SJ, Hampel T. Dementia with Lewy bodies. Clinical improvement under treatment with an acetylcholinesterase inhibitor]. Nervenarzt 2007; 78: $1052-1057$.

2 Tariot PN. Contemporary issues in the treatment of Alzheimer's disease: tangible benefits of current therapies. J Clin Psychiatry 2006; 67(Suppl 3): 15-22; quiz 23.

3 Jelic V, Kivipelto M, Winblad B. Clinical trials in mild cognitive impairment: lessons for the future. J Neurol Neurosurg Psychiatry 2006; 77: 429-438.

4 Raschetti R, Albanese E, Vanacore N, Maggini M. Cholinesterase inhibitors in mild cognitive impairment: a systematic review of randomised trials. PLoS Med 2007; 4: e338.

5 Bachurin S, Bukatina E, Lermontova N, Tkachenko S, Afanasiev A, Grigoriev V et al. Antihistamine agent Dimebon as a novel neuroprotector and a cognition enhancer. Ann N Y Acad Sci 2001; 939: 425-435.
6 Matveeva IA. Action of dimebon on histamine receptors. Farmakol Toksikol 1983; 46: $27-29$.

7 Shadurskii KS, Matveeva IA, I'iuchenok T. Therapeutic and protective properties of dimebon in burns. Farmakol Toksikol 1983; 46: 90-92.

8 Doody RS, Gavrilova SI, Sano M, Thomas RG, Aisen PS, Bachurin SO et al. Effect of dimebon on cognition, activities of daily living, behaviour, and global function in patients with mild-to-moderate Alzheimer's disease: a randomised, double-blind, placebo-controlled study. Lancet 2008; 372: 207-215.

9 Kieburtz K, McDermott MP, Voss TS, Corey-Bloom J, Deuel LM, Dorsey ER et al. A randomized, placebo-controlled trial of latrepirdine in Huntington disease. Arch Neurol 2010; 67: 154-160.

10 Contact: An Alzheimer's Disease Investigational Trial. Available at: http://www. contactstudy.com/ (accessed on 2010).

11 Horizon: A Huntington Disease Investigational Trial. Available at: http://www. horizontrial.com/index.php (accessed on 2010).

12 Editorial. Mechanism matters. Nat Med 2010; 16: 347.

13 Editorial. Learning from failure. Nat Rev Drug Discov 2010; 9: 499.

14 Bachurin SO, Ustyugov AA, Peters O, Shelkovnikova TA, Buchman VL, Ninkina NN. Hindering of proteinopathy-induced neurodegeneration as a new mechanism of action for neuroprotectors and cognition enhancing compounds. Dokl Biochem Biophys 2009; 428: 235-238.

15 Lermontova NN, Lukoyanov NV, Serkova TP, Lukoyanova EA, Bachurin SO. Dimebon improves learning in animals with experimental Alzheimer's disease. Bull Exp Biol Med 2000; 129: 544-546.

$16 \mathrm{Wu} \mathrm{J}, \mathrm{Li} \mathrm{Q}$, Bezprozvanny I. Evaluation of Dimebon in cellular model of Huntington's disease. Mol Neurodegener 2008; 3: 15.

17 Okun I, Tkachenko SE, Khvat A, Mitkin O, Kazey V, Ivachtchenko AV. From antiallergic to anti-Alzheimer's: molecular pharmacology of Dimebon. Curr Alzheimer Res 2010; 7: 97-112.

18 Zhang S, Hedskog L, Petersen CA, Winblad B, Ankarcrona M. Dimebon (latrepirdine) enhances mitochondrial function and protects neuronal cells from death. J Alzheimers Dis 2010; 21: 389-402.

19 Pieper AA, Xie S, Capota E, Estill SJ, Zhong J, Long JM et al. Discovery of a proneurogenic, neuroprotective chemical. Cell 2010; 142: 39-51.

20 Perez SE, Nadeem M, Sadleir KR, Matras J, Kelley CM, Counts SE et al. Dimebon alters hippocampal amyloid pathology in $3 \times \mathrm{Tg}-\mathrm{AD}$ mice. Int J Physiol Pathophysiol Pharmacol 2012; 4: 115-127.

21 Steele JW, Ju S, Lachenmayer ML, Liken J, Stock A, Kim SH et al. Latrepirdine stimulates autophagy and reduces accumulation of alpha-synuclein in cells and in mouse brain. Mol Psychiatry 2012; 18: 882-888.

22 Steele JW, Lachenmayer ML, Ju S, Stock A, Liken J, Kim SH et al. Latrepirdine improves cognition and arrests progression of neuropathology in an Alzheimer's mouse model. Mol Psychiatry 2012; 18: 889-897.

23 Burns A, Jacoby R. Dimebon in Alzheimer's disease: old drug for new indication. Lancet 2008; 372: 179-180.

24 Galenko-laroshevskii PA, Chekanova OA, Skibitskii VV, Bartashevich V, Khankoeva Al, Poliashova TI. Antiarrhythmic properties of dimebone. Biull Eksp Biol Med 1995; 119: 375-377.

25 Galenko-laroshevskii PA, Sheikh-Zade lu R, Chekanova OA, Melkumova ER, Bartashevich VV, Khankoeva Al. Effect of dimebone on coronary blood flow and myocardial contractibility. Biull Eksp Biol Med 1996; 121: 506-508.

26 Meneses A. Role of 5-HT6 receptors in memory formation. Drug News Perspect 2001; 14: 396-400.

27 Roth BL, Craigo SC, Choudhary MS, Uluer A, Monsma Jr. FJ, Shen Y et al. Binding of typical and atypical antipsychotic agents to 5-hydroxytryptamine-6 and 5-hydroxytryptamine-7 receptors. J Pharmacol Exp Ther 1994; 268: 1403-1410.

28 Mattson MP. Antigenic changes similar to those seen in neurofibrillary tangles are elicited by glutamate and $\mathrm{Ca}^{2+}$ influx in cultured hippocampal neurons. Neuron 1990; 4: 105-117.

29 Mills LR, Kater SB. Neuron-specific and state-specific differences in calcium homeostasis regulate the generation and degeneration of neuronal architecture. Neuron 1990; 4: 149-163.

30 Harkany T, Hortobagyi T, Sasvari M, Konya C, Penke B, Luiten PG et al. Neuroprotective approaches in experimental models of beta-amyloid neurotoxicity: relevance to Alzheimer's disease. Prog Neuropsychopharmacol Biol Psychiatry 1999; 23: $963-1008$

31 Kornhuber J, Weller M. Psychotogenicity and N-methyl-D-aspartate receptor antagonism: implications for neuroprotective pharmacotherapy. Biol Psychiatry 1997; 41: 135-144.

32 Palmer GC, Widzowski D. Low affinity use-dependent NMDA receptor antagonists show promise for clinical development. Amino Acids 2000; 19: 151-155.

33 Grigorev VV, Dranyi OA, Bachurin SO. Comparative study of action mechanisms of dimebon and memantine on AMPA- and NMDA-subtypes glutamate receptors in rat cerebral neurons. Bull Exp Biol Med 2003; 136: 474-477. 
34 Brown RE, Stevens DR, Haas HL. The physiology of brain histamine. Prog Neurobiol 2001; 63: 637-672.

35 Bachurin SO, Shevtsova EP, Kireeva EG, Oxenkrug GF, Sablin SO. Mitochondria as a target for neurotoxins and neuroprotective agents. Ann N Y Acad Sci 2003; 993: 334-344, discussion 345-339.

36 Lermontova NN, Redkozubov AE, Shevtsova EF, Serkova TP, Kireeva EG, Bachurin SO. Dimebon and tacrine inhibit neurotoxic action of beta-amyloid in culture and block L-type $\mathrm{Ca}(2+)$ channels. Bull Exp Biol Med 2001; 132: 1079-1083.

37 Schambra UB, Mackensen GB, Stafford-Smith M, Haines DE, Schwinn DA. Neuron specific alpha-adrenergic receptor expression in human cerebellum: implications for emerging cerebellar roles in neurologic disease. Neuroscience 2005; 135 507-523.

38 Zheng CJ, Han LY, Yap CW, Ji ZL, Cao ZW, Chen YZ. Therapeutic targets: progress of their exploration and investigation of their characteristics. Pharmacol Rev 2006; 58: 259-279.

39 Holmes C, Arranz MJ, Powell JF, Collier DA, Lovestone S. 5-HT2A and 5-HT2C receptor polymorphisms and psychopathology in late onset Alzheimer's disease. Hum Mol Genet 1998; 7: 1507-1509.

40 Thome J, Retz W, Baader M, Pesold B, Hu M, Cowen M et al. Association analysis of HTR6 and HTR2A polymorphisms in sporadic Alzheimer's disease. J Neural Transm 2001; 108: 1175-1180.

41 Schaffhauser H, Mathiasen JR, Dicamillo A, Huffman MJ, Lu LD, McKenna BA et al. Dimebolin is a 5-HT6 antagonist with acute cognition enhancing activities. Biochem Pharmacol 2009; 78: 1035-1042.

42 Shadurskaia SK, Khomenko Al, Pereverzev VA, Balaklevskii Al. Neuromediator mechanisms of the effect of the antihistamine agent dimebone on the brain. Biull Eksp Biol Med 1986; 101: 700-702.

43 Gankina EM, Porodenko NV, Kondratenko TI, Severin ES, Kaminka ME, Mashkovskii MD. The effect of antihistaminic preparations on the binding of labelled mepyramine, ketanserin and quinuclidinyl benzilate in the rat brain. Eksp Klin Farmakol 1993; 56: 22-24.

44 Hanin I. The AF64A model of cholinergic hypofunction: an update. Life Sci 1996; 58: $1955-1964$

45 Geldenhuys WJ, Darvesh AS, Dluzen DE. Dimebon attenuates methamphetamine, but not MPTP, striatal dopamine depletion. Neurochem Int 2012; 60: 806-808.

46 Vignisse J, Steinbusch HW, Bolkunov A, Nunes J, Santos Al, Grandfils C et al. Dimebon enhances hippocampus-dependent learning in both appetitive and inhibitory memory tasks in mice. Prog Neuropsychopharmacol Biol Psychiatry 2011 35: $510-522$.

47 Cowley TR, Gonzalez-Reyes RE, Richardson JC, Virley D, Upton N, Lynch MA. The age-related gliosis and accompanying deficit in spatial learning are unaffected by Dimebon. Neurochem Res 2012; 38: 1190-1195.

48 Webster SJ, Wilson CA, Lee CH, Mohler EG, Terry Jr AV, Buccafusco JJ. The acute effects of dimebolin, a potential Alzheimer's disease treatment, on working memory in rhesus monkeys. Br J Pharmacol 2011; 164: 970-978.

49 Giorgetti M, Gibbons JA, Bernales S, Alfaro IE, Drieu La Rochelle C, Cremers T et al. Cognition-enhancing properties of Dimebon in a rat novel object recognition task are unlikely to be associated with acetylcholinesterase inhibition or $\mathrm{N}$-methyl-D-aspartate receptor antagonism. J Pharmacol Exp Ther 2010; 333: 748-757.

50 Hirst WD, Stean TO, Rogers DC, Sunter D, Pugh P, Moss SF et al. SB-399885 is a potent, selective 5 -HT6 receptor antagonist with cognitive enhancing properties in aged rat water maze and novel object recognition models. Eur J Pharmacol 2006; 553: 109-119.

51 Bharadwaj PR, Verdile G, Barr RK, Gupta V, Steele JW, Lachenmayer ML et al. Latrepirdine (Dimebon) enhances autophagy and reduces intracellular GFPAbeta42 levels in yeast. J Alzheimers Dis 2012; 32: 949-967.

52 Chishti MA, Yang DS, Janus C, Phinney AL, Horne P, Pearson J et al. Early-onset amyloid deposition and cognitive deficits in transgenic mice expressing a double mutant form of amyloid precursor protein 695. J Biol Chem 2001; 276: 21562-21570.

53 Wang J, Ferruzzi MG, Varghese M, Qian X, Cheng A, Xie M et al. Preclinical study of dimebon on beta-amyloid-mediated neuropathology in Alzheimer's disease. $\mathrm{Mol}$ Neurodegener 2011; 6: 7.

54 Shelkovnikova TA, Ustyugov AA, Millership S, Peters O, Anichtchik O, Spillantini MG et al. Dimebon does not ameliorate pathological changes caused by expression of truncated (1-120) human alpha-synuclein in dopaminergic neurons of transgenic mice. Neurodegener Dis 2011; 8: 430-437.

55 De Jesus-Cortes $\mathrm{H}, \mathrm{Xu}$ P, Drawbridge J, Estill SJ, Huntington P, Tran S et al. Neuroprotective efficacy of aminopropyl carbazoles in a mouse model of Parkinson disease. Proc Natl Acad Sci USA 2012; 109: 17010-17015.

56 Bachurin SO, Shelkovnikova TA, Ustyugov AA, Peters O, Khritankova I, Afanasieva MA et al. dimebon slows progression of proteinopathy in gamma-synuclein transgenic mice. Neurotoxicol Res 2012; 22: 33-42.
57 Tesla R, Wolf HP, Xu P, Drawbridge J, Estill SJ, Huntington P et al. Neuroprotective efficacy of aminopropyl carbazoles in a mouse model of amyotrophic lateral sclerosis. Proc Natl Acad Sci USA 2012; 109: 17016-17021.

58 Combarros O, Rodriguez-Rodriguez E, Mateo I, Vazquez-Higuera JL, Infante J, Berciano $J$ et al. APOE dependent-association of PPAR-gamma genetic variants with Alzheimer's disease risk. Neurobiol Aging 2011; 32: 547 e541-546.

59 Cavalli A, Bolognesi ML, Minarini A, Rosini M, Tumiatti V, Recanatini M et al. Multitarget-directed ligands to combat neurodegenerative diseases. J Med Chem 2008; 51: 347-372.

60 Mosconi L. Brain glucose metabolism in the early and specific diagnosis of Alzheimer's disease. FDG-PET studies in $\mathrm{MCl}$ and AD. Eur J Nucl Med Mol Imaging 2005; 32: 486-510

61 Bubber P, Haroutunian V, Fisch G, Blass JP, Gibson GE. Mitochondrial abnormalities in Alzheimer brain: mechanistic implications. Ann Neurol 2005; 57: 695-703.

62 Cardoso SM, Santana I, Swerdlow RH, Oliveira CR. Mitochondria dysfunction of Alzheimer's disease cybrids enhances Abeta toxicity. J Neurochem 2004; 89: 1417-1426.

63 Wang X, Michaelis ML, Michaelis EK. Functional genomics of brain aging and Alzheimer's disease: focus on selective neuronal vulnerability. Curr Genomics 2010; 11: 618-633.

64 Naga KK, Geddes JW. Dimebon inhibits calcium-induced swelling of rat brain mitochondria but does not alter calcium retention or cytochrome $C$ release. Neuromolecular Med 2011; 13: 31-36.

65 Eckert SH, Eckmann J, Renner K, Eckert GP, Leuner K, Muller WE. Dimebon ameliorates amyloid-beta induced impairments of mitochondrial form and function. J Alzheimers Dis 2012; 31: 21-32.

66 Day M, Chandran P, Luo F, Rustay NR, Markosyan S, LeBlond D et al. Latrepirdine increases cerebral glucose utilization in aged mice as measured by $\left[{ }^{18} \mathrm{~F}\right]$-fluorodeoxyglucose positron emission tomography. Neuroscience 2011; 189: 299-304.

67 Bastianetto S, Krantic S, Quirion R. Polyphenols as potential inhibitors of amyloid aggregation and toxicity: possible significance to Alzheimer's disease. Mini Rev Med Chem 2008; 8: 429-435.

68 Bharadwaj PR, Dubey AK, Masters CL, Martins RN, Macreadie IG. A $\beta$ aggregation and possible implications in Alzheimer's disease pathogenesis. J Cell Mol Med 2009; 13: 412-421.

69 McLaurin J, Kierstead ME, Brown ME, Hawkes CA, Lambermon MH, Phinney AL et al. Cyclohexanehexol inhibitors of Abeta aggregation prevent and reverse Alzheimer phenotype in a mouse model. Nat Med 2006; 12: 801-808.

70 Yamashita M, Nonaka T, Arai T, Kametani F, Buchman VL, Ninkina $\mathrm{N}$ et al. Methylene blue and dimebon inhibit aggregation of TDP-43 in cellular models. FEBS Lett 2009; 583: 2419-2424.

71 Ustyugov AA, Shelkovnikova TA, Kokhan VS, Khritankova IV, Peters O, Buchman VL et al. Dimebon reduces the levels of aggregated amyloidogenic protein forms in detergent-insoluble fractions in vivo. Bull Exp Biol Med 2012; 152: 731-733.

72 Steele JW, Kim SH, Cirrito JR, Verges DK, Restivo JL, Westaway D et al. Acute dosing of latrepirdine (Dimebon), a possible Alzheimer therapeutic, elevates extracellular amyloid-beta levels in vitro and in vivo. Mol Neurodegener 2009; 4: 51.

73 Cirrito JR, Kang JE, Lee J, Stewart FR, Verges DK, Silverio LM et al. Endocytosis is required for synaptic activity-dependent release of amyloid-beta in vivo. Neuron 2008; 58: 42-51.

74 Tampellini D, Rahman N, Gallo EF, Huang Z, Dumont M, Capetillo-Zarate E et al. Synaptic activity reduces intraneuronal Abeta, promotes APP transport to synapses, and protects against Abeta-related synaptic alterations. J Neurosci 2009; 29: 9704-9713.

75 Klionsky DJ, Emr SD. Autophagy as a regulated pathway of cellular degradation Science 2000; 290: 1717-1721.

76 Ivachtchenko AV, Frolov EB, Mitkin OD, Tkachenko SE, Okun IM, Khvat AV. Synthesis and biological activity of 5-styryl and 5-phenethyl-substituted 2,3,4,5-tetrahydro-1H-pyrido[4,3-b]indoles. Bioorg Med Chem Lett 2010; 20: $78-82$.

77 Glennon RA, Dukat M, Grella B, Hong S, Costantino L, Teitler M et al. Binding of beta-carbolines and related agents at serotonin (5-HT(2) and 5-HT(1A)) dopamine $(\mathrm{D}(2))$ and benzodiazepine receptors. Drug Alcohol Depend 2000; 60: 121-132.

78 Du W, Aloyo VJ, Harvey JA. Harmaline competitively inhibits $\left[{ }^{3} \mathrm{H}\right] \mathrm{MK}-801$ binding to the NMDA receptor in rabbit brain. Brain Res 1997; 770: 26-29.

79 Herraiz T, Gonzalez D, Ancin-Azpilicueta C, Aran VJ, Guillen H. Beta-carboline alkaloids in Peganum harmala and inhibition of human monoamine oxidase (MAO). Food Chem Toxicol 2010; 48: 839-845.

80 Yang YJ, Lee JJ, Jin CM, Lim SC, Lee MK. Effects of harman and norharman on dopamine biosynthesis and L-DOPA-induced cytotoxicity in PC12 cells. Eur J Pharmacol 2008; 587: 57-64. 
81 Pimpinella G, Palmery M. Interaction of beta-carbolines with central dopaminergic transmission in mice: structure-activity relationships. Neurosci Lett 1995; 189: 121-124.

82 Gockler N, Jofre G, Papadopoulos C, Soppa U, Tejedor FJ, Becker W. Harmine specifically inhibits protein kinase DYRK1A and interferes with neurite formation. FEBS J 2009; 276: 6324-6337.

83 Pfizer and Medivation Announce Results from Two Phase 3 Studies In Dimebon (latrepirdine) Alzheimer's Disease Development Program. Available at: http://investors. medivation.com/releasedetail.cfm?ReleaselD $=448818$ (accessed on 2010).

84 Concert: An Alzheimer's Disease Investigational Trial. Available at: http:// concertstudy.com/index.html (accessed on 2010).
85 Constellation: An Alzheimer's disease Research Study. Available at: http:// www.constellationstudy.com/index.php (accessed on 2010).

86 Morozova MA, Beniashvili AG, Lepilkina TA, Rupchev GE. Double-blind placebocontrolled randomized efficacy and safety trial of add-on treatment of dimebon plus risperidone in schizophrenic patients during transition from acute psychotic episode to remission. Psychiatr Danub 2012; 24: 159-166.

(C) This work is licensed under a Creative Commons AttributionNonCommercial-ShareAlike 3.0 Unported License. To view a copy of this license, visit http://creativecommons.org/licenses/by-nc-sa/3.0/ 